\title{
Microstructure of Passive Film on Steel in Synthetic Concrete Pore Solution in Presence Chloride and Nitrite
}

\author{
Xiaozhen Li, Junzhe Liu*, Jianmin Wang, Jundi Geng \\ NingBo University, Faculty of Architectural, Civil Engineering and Environment, Ningbo, Zhejiang \\ 315211, China \\ *E-mail: liujunzhe@nbu.edu.cn
}

doi: $10.20964 / 2019.09 .43$

Received: 5 May 2019 / Accepted: 24 June 2019 / Published: 31 July 2019

\begin{abstract}
Microscopic characteristics of passive films on steel surfaces under three corrosion conditionschloride, carbonated and compound solutions-were studied by X-ray photoelectron spectroscopy (XPS) and X-ray diffraction (XRD). The influence of $\left.n\left(\mathrm{NO}_{2}{ }^{-}\right) / \mathrm{n}_{(\mathrm{Cl}}{ }^{-}\right)$on the corrosion current was evaluated by the anodic polarization method. Experiments revealed that nitrite expanded the range of steel bar passivation and effectively prevented steel bar corrosion caused by chloride ions. The results showed that in the simulated chloride solution, a complete passivation film was formed on the surface of the steel wafers under the condition of $\mathrm{n}\left(\mathrm{NO}_{2}^{-}\right) / \mathrm{n}\left(\mathrm{Cl}^{-}\right)=1.5$. In the simulated carbonated solution, when the content of sodium nitrite was $3 \%$, the passivation film on the surfaces of steel wafers was completely formed. Steel corrosion was substantial in the compound solution, and the passivation effect was obvious when $n\left(\mathrm{NO}_{2}^{-}\right) / n\left(\mathrm{Cl}^{-}\right)=2.0$. With the addition of sodium nitrite, the main components of the passivation film were $\mathrm{FeOOH}, \mathrm{FeO}$ and $\mathrm{Fe}_{3} \mathrm{O}_{4}$. In the outer layer, $\mathrm{FeOOH}$ was the main component, whereas $\mathrm{FeO}$ and $\mathrm{Fe}_{3} \mathrm{O}_{4}$ were found in relatively lower proportions. The inner layer was relatively dense because $\mathrm{FeO}$ and $\mathrm{Fe}_{3} \mathrm{O}_{4}$ were the main components. Sodium nitrite can increase the forward reaction rate of passivation film formation, and the thickness of passivation film can be controlled by changing the content of the reaction material. After a complete passivation film was formed on the surface of the steel, further reaction between the "external" material and the elemental iron inside the passivation film was hindered. $\left(\mathrm{NaFeO}_{2}\right)_{2}$ in the solution was easily hydrolyzed in water to form $\mathrm{FeOOH}$, which precipitated and accumulated on the outer layer of the passivation film to form the "double-layer structure".
\end{abstract}

Keywords: chloride; carbonation; nitrite; passive film; microstructure

\section{$\underline{\text { FULL TEXT }}$}


(C) 2019 The Authors. Published by ESG (www.electrochemsci.org). This article is an open access article distributed under the terms and conditions of the Creative Commons Attribution license (http://creativecommons.org/licenses/by/4.0/). 